\title{
DESEMPENHO EM CAMPO DE PLANTAS ISOLADAS DE ARROZ HÍBRIDO EM FUNÇÃO DA QUALIDADE FISIOLÓGICA DAS SEMENTES ${ }^{1}$
}

\author{
FABIO MIELEZRSKI ${ }^{2}$, LUIS OSMAR BRAGA SCHUCH ${ }^{3}$, SILMAR TEICHERT PESKE \\ LUÍS EDUARDO PANOZZO ${ }^{5}$, RUDINELI RIBEIRO CARVALHO ${ }^{6}$, JACSON ZUCHI ${ }^{7}$
}

\begin{abstract}
RESUMO - O trabalho teve como objetivo avaliar o efeito do vigor de sementes sobre características agronômicas em plantas de arroz, híbrido Avaxi, cultivadas isoladamente. Utilizou-se dois lotes de sementes, procedentes da empresa RiceTec $\AA$, caracterizados como alto e baixo vigor. A semeadura foi realizada direto no campo, em covas espaçadas de $50 \mathrm{~cm}$ de forma a manterem as plantas isoladas. Foi feita a semeadura com 10 sementes por cova para permitir posterior desbaste, deixando ao final uma planta por cova. Utilizou-se o delineamento experimental de blocos ao acaso com 20 repetições. Testaram-se dois tratamentos; plantas originadas de sementes de alto e de baixo vigor, sendo cada parcela constituída por uma única planta. A correção da fertilidade foi realizada de acordo com análise de solo e o controle de plantas invasoras realizado manualmente. Avaliou-se: altura das plantas aos 60 e 115 dias após a emergência, na ocasião da colheita o número de panículas por planta, área foliar, massa da matéria seca da parte aérea da planta, número de grãos por panícula, número de grãos por planta, peso de 1000 sementes e rendimento de grãos por planta. Conclui-se que a qualidade fisiológica das sementes utilizadas para o estabelecimento das plantas, afeta o desempenho das plantas adultas. Sementes de alto vigor originam plantas com maior potencial fisiológico o que se refle em maior crescimento e maior rendimento de grãos.
\end{abstract}

Termos para indexação: Oryza sativa, potencial fisiológico.

\section{FIELD PERFORMANCE OF ISOLATED PLANTS OF HYBRID RICE IN FUNCTION OF THE SEED PHYSIOLOGICAL QUALITY}

\begin{abstract}
The work had the objective of evaluating the effects of seed vigor over several agronomic characteristics of hybrid rice plants. The experiment was conducted in the didactic experimental area of the Federal University of Pelotas (UFPEL). It was used two seed lots, which belong to the Ricetec ${ }^{\circledR}$, characterized by presenting low and high vigor. The sowing was conducted directly on the field, in hollows distant $50 \mathrm{~cm}$ from each other, in order to isolate the plants. It was sowed 10 seed per hollow to allow posterior looping, leaving one plant per hollow at the end. The experiment was developed by a randomized completely block design, with 20 repetitions. Two treatments were tested; plants which were originated from low and high vigor seeds, formatting parcels constituted by only one plant. The soil fertility correction was accomplished by analyzing the soil, and the weed control was accomplished manually. The following parameters were evaluated: plant height at 60 and 115 days after plants emergence number of panicles per plant, leaf area, dry matter of the aerial
\end{abstract}

${ }^{1}$ Submetido em 26/02/2008. Aceito em 20/08/2008. Parte da dissertação de mestrado do primeiro autor que será apresentada à FAEM-UFPel.

${ }^{2}$ Mestre em Ciência e Tecnologia de Sementes, UFPel/FAEM, fabioagronomia@ibest.com.br.

${ }^{3}$ Professor, Dr., Departamento de Fitotecnia, UFPel/FAEM, Caixa Postal 354, CEP: 96010-900.
${ }^{4}$ Professor, Dr., Departamento de Fitotecnia, UFPel/FAEM, Caixa Postal 354, CEP: 96010-900.

${ }^{5}$ Mestrando em Fitossanidade, UFPel/FAEM, lepanozzo@gmail.com.

${ }^{6}$ Mestre em Ciência e Tecnologia de Sementes, UFPel/FAEM, rudinelicarvalho@bol.com.br..'Mestre em Ciência e Tecnologia de Sementes, UFPel/FAEM. 
part, number of grains per panicle, number of grains per plant, weight of 1000 seeds and plant yield. It was concluded that the seed physiological quality used for the plants establishment affected the performance of the adult plants. Seeds of high vigor originated plants with higher physiological potential which reflected on a higher growing and yield per plant.

Index terms: Oryza sativa, physiological potential, performance.

\section{INTRODUÇÃO}

O arroz (Oryza sativa L.) é um dos cereais mais cultivados no mundo, sendo parte da alimentação básica para mais da metade da população. No Brasil, a cultura corresponde a $20 \%$ da produção de grãos. No Rio Grande do Sul, a área total semeada no estado gira em torno de 954,4 mil hectares, com uma produtividade média de $6.610 \mathrm{Kg} \cdot$ ha $^{-1}$ (CONAB, 2008).

Atualmente o arroz híbrido vem crescendo em área semeada no Brasil, por proporcionar acréscimos de $20 \%$ na produtividade das lavouras e permitir baixar a densidade de semeadura (150 kg.ha-1 para $\left.50 \mathrm{~kg} \cdot \mathrm{ha}^{-1}\right)$. O vigor híbrido em arroz resultante da heterose, explorado comercialmente, vem sendo uma das mais importantes aplicações técnicas da genética na agricultura. Este fenômeno contribui não somente para segurança alimentar, mas também beneficia diretamente o ambiente. Segundo Alcochete (2005), o desenvolvimento de híbridos de arroz representa uma revolução no incremento de produtividade da cultura e a combinação de linhagens elite de programas de melhoramento de arroz híbrido pode elevar a produtividade de linhagens puras de arroz.

A grande maioria das definições de vigor caracteriza as tarefas do processo germinativo como sendo a rapidez, a uniformidade de germinação e a perfeição da plântula produzida (Höfs, 2003). Para a AOSA (1983), "vigor de sementes compreende aquelas propriedades que determinam o potencial para uma emergência rápida e uniforme, para o desenvolvimento de plântulas normais, sob uma ampla faixa de condições ambientais".

Vigor é um dos atributos da qualidade fisiológica, sendo o estabelecimento e desempenho das culturas em condições de campo objeto de pesquisa. Sementes com baixo vigor podem provocar reduções na emergência em campo, na velocidade de emergência e no tamanho inicial das plantas (Schuch, 2006). O vigor das sementes modifica o desenvolvimento vegetativo e está freqüentemente relacionado ao rendimento em culturas que são colhidas no estádio vegetativo ou durante o início do desenvolvimento reprodutivo. Várias pesquisas mostram a influência do vigor das sementes também no rendimento de grãos nas culturas. Em milho, pode ocorrer até $8 \%$ de redução na produtividade com a utilização de sementes de baixo vigor (Grabe, 1966). Trabalhos publicados mais recentemente, (Schuch, 2006), demonstraram que sementes de soja com baixo vigor podem provocar reduções na emergência em campo, na velocidade de emergência e no tamanho inicial das plantas. Kolchinski (2003) observou redução do rendimento de $28 \%$ de grãos em função da variação do vigor de sementes em populações de soja. Schuch e Finatto (2006), em experimento com comportamento de plantas isoladas de soja verificaram redução do rendimento em função da variação de vigor de sementes. Em arroz, comunidades de plantas originadas de sementes de alto vigor apresentam rendimento superior a $20 \%$ em relação às comunidades de plantas originadas de sementes de baixo vigor (Melo et al., 2006).

A maior velocidade na emergência e a produção de plântulas com maior tamanho pode proporcionar às plantas provenientes das sementes vigorosas uma vantagem inicial no aproveitamento de água, luz e nutrientes. As respostas das plantas à competição por luz incluem mudanças na arquitetura da planta, no crescimento e desenvolvimento, na absorção e distribuição de assimilados (Almeida e Mundstock, 1998). Analisando a influência de quatro níveis de radiação solar $(30,50,70$ e $100 \%)$ em plantas de soja, Menges et al. (1989) observaram que as taxas de crescimento da cultura diminuíram com a redução da radiação solar, ocasionadas por menores áreas foliares das plantas.

Assim, o trabalho teve como objetivo avaliar o efeito do vigor de sementes sobre o comportamento de plantas de arroz híbrido, cultivadas isoladamente.

\section{MATERIAL E MÉTODOS}

O experimento foi realizado na Área Experimental e Didática do Departamento de Fitotecnia da Faculdade de 
Agronomia Eliseu Maciel (FAEM) da Universidade Federal de Pelotas, Pelotas, RS. Utilizou-se dois lotes de sementes de arroz, híbrido Avaxi, caracterizados como alto e baixo vigor, procedentes da empresa RiceTec $\circledR$.

A semeadura foi realizada diretamente no campo, em covas espaçadas de $50 \mathrm{~cm}$ de forma a manter as plantas isoladas. Foram semeadas 10 sementes por cova para permitir posterior desbaste, retirando as plântulas mais precoces no lote de baixo vigor e as mais tardias no lote de alto vigor, com o propósito de utilizar a plântula emergida no dia de maior freqüência de emergência para cada um dos níveis de vigor, deixando ao final uma planta por cova. A correção da fertilidade foi realizada de acordo com análise de solo baseada nas recomendações (Rolas, 1994), sendo incorporado no solo o adubo NPK na semeadura. A adubação nitrogenada foi dividida em três aplicações: 1/3 antes da entrada de água, 1/3 na diferenciação do primórdio floral e $1 / 3$ no florescimento. Não foi necessário tratamento fitossanitário. O controle das plantas daninhas foi realizado manualmente, o mais precoce possível para evitar o efeito da competição inter e intraespecífica na comunidade. Durante o experimento foi realizado o controle do percevejo do grão (Oebalus poecilus) com a aplicação de produto fosforado não sistêmico indicado para a cultura do arroz irrigado.

Foi avaliada a altura das plantas $(\mathrm{cm})$ aos 60 dias após a emergência e na maturação (115 dias após a emergência), número de panículas por planta, área foliar, massa da matéria seca da parte aérea, número de grãos por planta, número de grãos por panícula por planta, rendimento de grãos por planta (g) e peso de 1000 sementes por planta.

Essa avaliação foi feita com a utilização de régua graduada e para a área foliar usou-se o Licor LI2600. Para a determinação da massa da matéria seca da parte aérea da planta utilizou-se o método de estufa a $65,5^{\circ} \mathrm{C}$ até peso constante. As panículas de cada planta foram trilhadas manualmente e, em seguida, determinado o número de grãos por panícula. Após secagem foi determinado o peso de 1000 sementes e o rendimento de grãos, utilizando-se balança centesimal. A determinação do grau de umidade foi realizada pelo método de estufa a $105^{\circ} \mathrm{C} \pm 3^{\circ} \mathrm{Cpor} 24$ horas, de acordo com as Regras de análise de sementes (Brasil, 1992).

Utilizou-se o delineamento experimental em blocos ao acaso com 20 repetições. Os tratamentos testados foram plantas originadas de sementes de alto e baixo vigor, respectivamente, sendo cada parcela constituída por uma única planta. Na execução das análises estatísticas foi utilizado o sistema de análise estatística para Windows - WinStat Versão 2.0 (Machado e Conceição, 2003), as comparações de médias foram realizadas pelo teste de Duncan, a 5\% de probabilidade.

\section{RESULTADOS E DISCUSSÃO}

$\mathrm{Na}$ caracterização inicial dos lotes de sementes de arroz híbrido, o lote de alto vigor apresentou germinação de $97 \%$, o teste de frio $88 \%$ e o envelhecimento acelerado de $93 \%$. O lote de baixo vigor apresentou germinação de $83 \%$, o teste de frio $62 \%$ e o envelhecimento acelerado $67 \%$.

As sementes de alto vigor produziram plantas que apresentaram desempenho superior às originadas de sementes de baixo vigor. Na Tabela 1 constata-se que as plantas originadas de sementes de alto vigor apresentaram maior altura de plantas, aos 60 e 115 dias após a emergência. Comportamento semelhante foi observado por Schuch e Finatto (2006), onde plantas de soja cultivadas isoladamente, provenientes de sementes de alta qualidade fisiológica, apresentaram altura superior às plantas originadas de sementes com qualidade inferior. Schuch et al. (2000), em aveia preta, observaram que sementes de menor vigor reduzem, retardam e desuniformizam a emergência das plântulas em campo, enquanto que sementes de vigor mais elevado produzem plântulas com maior tamanho inicial, o que proporciona maiores taxas de crescimento da cultura. Edje \& Burris (1971) trabalhando com soja, relataram que sementes menos vigorosas de soja emergiram mais lentamente e produziram plantas com menor tamanho inicial. Provavelmente, sementes de baixo vigor apresentam menor habilidade em originar plântulas vigorosas sob condições ambientais desfavoráveis e tendem a produzir plântulas fracas com reduzido potencial fisiológico.

Destacou-se também que as sementes de alto vigor produziram plantas com área foliar e massa da matéria seca da parte aérea, $19 \%$ e $19 \%$ respectivamente, superiores às sementes de baixo vigor (Tabela 1). Efeitos do vigor das sementes sobre a produção de matéria seca e área foliar também foram constatados em outros trabalhos em que as plantas estudadas estavam em comunidade (Schuch, 1999; Machado, 2002; Höfs, 2003; Kolchinski, 2003). Segundo Dan et al. (1987), as sementes vigorosas apresentam maior capacidade de transformação, suprimento das reservas nos tecidos de armazenamento e maior incorporação dessas pelo eixo embrionário. Isto pode resultar em emergência mais rápida e uniforme, e plântulas com maior tamanho inicial, influenciando dessa forma, a área foliar e o acúmulo de matéria seca. 
TABELA 1. Altura de planta (cm) aos 60 e 115 dias após a emergência (DAE); massa da matéria seca da parte aérea (g) e área foliar $\left(\mathrm{cm}^{2}\right)$ aos 115 dias após a emergência (DAE), de plantas isoladas de arroz híbrido, originadas de sementes de alto e baixo vigor.

\begin{tabular}{ccccc}
\hline Vigor & $\begin{array}{c}\text { Altura de planta aos } \\
60 \text { DAE }\end{array}$ & $\begin{array}{c}\text { Altura de planta aos } \\
115 \text { DAE }\end{array}$ & $\begin{array}{c}\text { Massa da matéria } \\
\text { seca da parte aérea } \\
\text { aos 115 DAE }\end{array}$ & $\begin{array}{c}\text { Área foliar aos } \\
115 \text { DAE }\end{array}$ \\
\hline Alto & $99 \mathrm{a}^{*}$ & $113 \mathrm{a}$ & $92.36 \mathrm{a}$ & $6849 \mathrm{a}$ \\
Baixo & $94 \mathrm{~b}$ & $110 \mathrm{~b}$ & $74.65 \mathrm{~b}$ & $5505 \mathrm{~b}$ \\
\hline $\mathrm{CV}$ & 4,6 & 1,6 & 21,0 & 17,6 \\
\hline
\end{tabular}

*Médias seguidas pela mesma letra na coluna não diferem estatisticamente pelo teste de Duncan a 5\% de probabilidade.

Plantas que emergem tardiamente por serem provenientes de sementes menos vigorosas acabam sendo sombreadas pelas plantas que emergem precocemente (resultantes de sementes de alto vigor) ocasionando redução da captação de luz pelas plantas menores e, conseqüentemente, redução da taxa fotossintética (Cervieri Filho, 2005). Pinthus \& Kimel (1979) observaram que as plântulas de soja que emergiram posteriormente apresentaram as primeiras folhas trifolioladas menores em relação às plântulas provenientes das sementes com maior vigor, resultando em menor taxa de acúmulo de matéria seca durante o período de crescimento. No estudo do comportamento individual de plantas em comunidades de soja, também se verificou que plantas provenientes de sementes de alto vigor apresentaram maiores índices de área foliar na floração em relação às plantas provenientes das sementes com baixo vigor (Kolchinski (2003). O alto vigor inicial proporciona melhores condições de captação de energia solar, favorecendo o desenvolvimento das plantas (Almeida et al., 1998).

As plantas originadas de sementes de melhor qualidade fisiológica também se mostraram superiores quanto ao peso de 1000 sementes, maior número de panículas por planta, número de grãos por planta e rendimento de grãos quando comparadas às plantas originadas de sementes de baixo vigor (Tabela 2). Destaca-se que as sementes de alto vigor produziram plantas com número de panículas por planta e rendimento de grãos, $13 \%$ e $22 \%$ respectivamente superiores às sementes de baixo vigor. Ambos os tratamentos apresentaram elevado número de panículas e rendimento de grãos por planta, o que pode ser explicado pelas plantas terem se desenvolvido isoladas, sem competição por plantas vizinhas.

TABELA 2. Número de panículas, número de grãos por planta, número de grãos por panícula, peso de 1000 sementes e rendimento de grãos (g) em plantas isoladas de arroz híbrido, originadas de sementes de alto e baixo vigor.

\begin{tabular}{lccccc}
\hline Vigor & $\mathrm{N}^{\mathrm{o}}$ panículas & $\begin{array}{c}\mathrm{N}^{\mathrm{o}} \text { de grãos } \\
\text { por planta }\end{array}$ & $\begin{array}{c}\mathrm{N}^{\mathrm{o}} \text { de grãos } \\
\text { por panícula }\end{array}$ & $\begin{array}{c}\text { Peso de } 1000 \\
\text { sementes }\end{array}$ & $\begin{array}{c}\text { Rend. de } \\
\text { Grãos }\end{array}$ \\
\hline Alto & $61 \mathrm{a}^{*}$ & $8693 \mathrm{a}$ & $135,85 \mathrm{a}$ & $24.48 \mathrm{a}$ & $217.33 \mathrm{a}$ \\
Baixo & $53 \mathrm{~b}$ & $6788 \mathrm{~b}$ & $135,47 \mathrm{a}$ & $22.77 \mathrm{~b}$ & $169.70 \mathrm{~b}$ \\
\hline $\mathrm{CV}$ & 16,8 & 13,6 & 9,3 & 3,8 & 13,0 \\
\hline
\end{tabular}

*Médias seguidas pela mesma letra na coluna, não diferem estatisticamente pelo teste de Duncan a 5\% de probabilidade.

O maior rendimento de grãos proveniente da utilização de sementes alta qualidade fisiológica, também já foi observado em arroz irrigado (Melo, 2005) e em aveia branca (Machado, 2002). Höfs et al (2004), estudando o efeito da qualidade fisiológica das sementes e da densidade de semeadura sobre o rendimento de grãos e qualidade industrial em arroz, verificaram que o rendimento de grãos foi afetado pelo nível de qualidade fisiológica das sementes. Os mesmos 
autores afirmam que a redução do rendimento de grãos está, provavelmente, associada à maior desuniformidade de emergência e, conseqüentemente, ao maior grau de competição intraespecífica que estariam sujeitas as plantas emergidas mais tardiamente, o que se refletiria em redução nos componentes do rendimento.

Em soja, Scheeren (2002) constatou aumento de 9\% na produtividade pelo uso de sementes de alto vigor. Comportamento semelhante foi verificado por Schuch e Finatto (2006), em plantas isoladas de soja, onde as provenientes de sementes de alta qualidade fisiológica apresentaram maior número de vagens por planta, peso de 1000 sementes e rendimento de grãos. Na cultura de trigo, sob condições não competitivas, diferenças no vigor das sementes resultaram em diferenças na taxa de crescimento, sendo que a vantagem inicial para as plantas provenientes de sementes de alta qualidade foi suficiente para resultar em maior rendimento final de grãos (Khah et al., 1989).

Um dos fatores que poderia ter contribuído para os maiores rendimentos de grãos obtidos em plantas isoladas de arroz híbrido, oriundas de sementes de alta qualidade fisiológica, seria a produção de plantas com maior altura, área foliar e massa de matéria seca da parte aérea, permitindo às plantas de alto vigor melhores condições de captação de energia solar e um possível aumento da radiação fotossinteticamente ativa das folhas, possibilitando assim um maior potencial fisiológico, o qual se refletiu em maior crescimento e maior rendimento de grãos.

O número de grãos por panícula (Tabela 2) não foi afetado pela qualidade fisiológica das sementes que originaram as plantas, o que também foi constatado por Schuch e Finatto (2006) em plantas isoladas de soja, cujo número de grãos por vagem também não foi influenciado pela qualidade fisiológica das sementes.

\section{CONCLUSÕES}

A qualidade fisiológica das sementes de arroz híbrido Avaxi, utilizadas para o estabelecimento das plantas, afeta o desempenho das plantas adultas;

Plantas isoladas de arroz híbrido originadas de sementes de alto vigor apresentam produção de grãos superior a $20 \%$ em comparação às plantas originadas de sementes de baixo vigor. Sementes de alto vigor originam plantas com maior potencial fisiológico que se reflete em maior crescimento e maior rendimento de grãos.

\section{AGRADECIMENTOS}

À Fapergs, CNPq e a CAPES pelo apoio financeiro e a RiceTec ${ }^{\circledR}$ pela cessão das sementes.

\section{REFERÊNCIAS}

ALCOCHETE, A.A.N. Diversidadegenética e mapeamento de qtls do sistema gênico de macho-esterilidade termosensível (tgms) do genoma de arroz (Oryza sativa L.). 2005. 145 f. Tese - Universidade de Brasília, Brasília.

ALMEIDA, A.A.; MUNDSTOCK, C.M. Afilhamento em comunidades de cereais de estação fria é afetado pela qualidade da luz? Ciência Rural, v.8, n.3, p.511-519, 1998.

AOSA-ASSOCIATION OF OFFCIAL SEED ANALYSTS. Seed vigor testing handbook. In: The handbook on seed testing. East Lansing, 1983, 88p. (Contribution, 32).

BRASIL. Ministério da Agricultura e Reforma Agrária. Regras para análises de sementes. Brasília, DF: SNDA/ DNDV/CLAV, 1992. 256p.

CERVIERI FILHO, E. Desempenho de plantas oriundas de sementes de alto e baixo vigor dentro de uma população de soja. 2005. $42 \mathrm{f}$. Tese (Doutorado em Ciência e Tecnologia de Sementes) - Faculdade de Agronomia Eliseu Maciel, Universidade Federal de Pelotas, Pelotas.

CONAB. Arroz - Rio Grande do Sul: área plantada e produtividade: safras 2005/2006. Brasília, 2008. Disponível em: <http://www.conab.gov.br/conabweb/download/safra/ ArrozSerieHist.xls.>. Acesso em: 8 mai 2008.

DAN, E.L.; MELLO, V.D.C.; WETZEL, C.T.; POPINIGIS, F.; SOUZA, E.P. Transferência de matéria seca como método de avaliação do vigor de sementes de soja. Revista Brasileira de Sementes, v.9, n.3, p.45-55, 1987.

EDJE, O.T.; BURRIS, J.S. Effects of soybean seed vigor on field performance. Agronomy Journal, v.63, n.4, p.536538, 1971.

GRABE, D.F. Significance of seedling vigor em corn. In: ANNUAL HYBRID CORN INDUSTRY - RESEARCH CONFERENCE, 21., 1966, Chicago. Proceedings... 1966. p.39-44

HÖFS, A. Emergência e crescimento de plântulas de arroz em resposta à qualidade fisiológica das sementes. 2003. 44

f. Tese (Doutorado em Ciência e Tecnologia de Sementes)

- Faculdade de Agronomia Eliseu Maciel, Universidade Federal de Pelotas, Pelotas.

HÖFS, A.; SCHUCH, L.O.B.; PESKE, S.T.; BARROS, A.C.S.A. Efeito da qualidade fisiológica das sementes e 
da densidade de semeadura sobre o rendimento de grãos e qualidade industrial em arroz. Revista Brasileira de Sementes, v.26, n.2, p.55-62, 2004.

KHAH, E.M.; ROBERTS, E.H.; ELLIS, R.H. Effects on seed ageing on growth and yield of spring wheat at different plant-population densities. Field Crops Research, v.20, p.175-190, 1989.

KOLCHINSKI, E.M. Vigor de sementes e competição intraespecífica em soja. 2003. 44 f. Tese (Doutorado em Ciência e Tecnologia de Sementes) - Faculdade de Agronomia Eliseu Maciel, Universidade Federal de Pelotas, Pelotas.

MACHADO, A.A.; CONCEIÇÃO, A.R. Sistema de análise estatística para windows. WinStat. Versão 2.0. Pelotas: UFPel, 2003.

MACHADO, R.F. Desempenho de aveia-branca (Avena sativa L.) em função do vigor de sementes e população de plantas. 2002. 46 f. Dissertação (Mestrado em Ciência e Tecnologia de Sementes) - Faculdade de Agronomia Eliseu Maciel, Universidade Federal de Pelotas, Pelotas.

MELO, P.T.B.S.; SCHUCH, L.O.B.; ASSIS, F.N; CONCENÇO, G. Comportamento Individual de plantas originadas de sementes com diferentes níveis de qualidade fisiológica em populações de arroz irrigado. Revista Brasileira de Sementes, v. 28, n.2, p.84-94, 2006.

MELO, P.T.B.S. Desempenho individual e de populações de plantas de arroz relacionado ao vigor de sementes. 2005. Tese. 46 f. (Doutorado em Ciência e Tecnologia de Sementes) - Faculdade de Agronomia Eliseu Maciel, Universidade Federal de Pelotas, Pelotas.

MENGES, E.A.; LOPES, N.F.; OLIVA, M.A. Crescimento e conversão de energia solar em soja cultivada sob quatro níveis de radiação solar. Pesquisa Agropecuária Brasileira, v.24, n.9, p.1065-1072, 1989.

PINTHUS, M.J.; KIMEL, U. Speed of germination as a criterion of seed vigor in soybeans. Crop Science, v.19, p.219-292, 1979.

ROLAS. Recomendações de adubação e calagem para os Estados do Rio Grande do Sul e Santa Catarina. Passo Fundo: SBCS-Núcleo Regional Sul, 1994. 223p.

SCHEEREN, B. Vigor de sementes de soja e produtividade. 2002. 45 f. Tese - Faculdade de Agronomia Eliseu Maciel, Universidade Federal de Pelotas, Pelotas.

SCHUCH, L.O.B. Vigor de sementes e aspectos fisiológicos da produção em Aveia preta (Avena strigosa Schreb). 1999. 127 f. Tese (Doutorado em Ciência e Tecnologia de Sementes) - Faculdade de Agronomia Eliseu Maciel, Universidade Federal de Pelotas, Pelotas.

SCHUCH, L.O.B.; NEDEL, J.L.; ASSIS, F.N.; MAIA, M.S.; ROSENTHAL, M.D. Emergência no campo e crescimento inicial de Aveia Preta em resposta ao vigor das sementes. Revista Brasileira de Agrociência, v.6, n.2, p. 97-101, 2000.

SCHUCH, L.O.B. Maximizando a produção com sementes de alto vigor. Revista SEED News, v.10, n.3, p.8-11, 2006.

SCHUCH, L.O.B.; FINATTO, J.A. Comportamento de plantas isoladas de soja em função da qualidade fisiológica das sementes In: CONGRESSO DE INICIAÇÃO CIENTÍFICA, 14., E ENCONTRO DE PÓS-GRADUAÇÃO, 7., 2006, Pelotas. Anais.... Pelotas: Editora e Gráfica Universitária UFPel, 2006. 1 CD-ROOM. 